\title{
Perceptions of HIV-Related Stigma in Portugal Among MSM With HIV Infection and an Undetectable Viral Load
}

\author{
Henrique Pereira, PhD $^{*}$ \\ Denise Caldeira, MSc \\ Samuel Monteiro, PhD
}

We explored perceptions of HIV-related stigma using a qualitative approach based on the findings of in-depth e-mail asynchronous interviews with 37 self-identified Portuguese men who have sex with men (MSM) with HIVinfection and undetectable viral loads. Participants were asked to answer an online interview. Major findings concerned external perceptions of HIV-related stigma, HIV status disclosure, the impact of HIV on everyday life, the presence of double discrimination, and general perceptions of HIVrelated stigma. Results revealed (a) stigmatizing and discriminatory behaviors and practices in psychosocial and inter-relational events, but not in accessing and receiving health care; (b) double exposure to stigma associated with being gay and having HIV; and (c) undetectability as an autonomous identity with important connections to social and interpersonal interactions. An important implication was related to multilevel risk perceptions and the psychosocial complexity and challenges of HIV infection. In Portugal, HIV is still a socially disabling disease.

(Journal of the Association of Nurses in AIDS Care, 口, 1-15) Copyright (C) 2017 Association of Nurses in AIDS Care

Key words: HIV-related stigma, men who have sex with men, Portugal, undetectable viral load

T here were an estimated 54,297 HIV-infected individuals in Portugal in 2016 (Departamento de Doenças Infecciosas [DDI], 2016), and an HIV prevalence rate of $0.82 \%$ among those ages 15 to 49 years, signifying that Portugal had one of the highest HIV prevalence rates in Western Europe (Joint United Nations Programme on HIV/AIDS, 2013). In addition, $81.7 \%$ of people diagnosed with HIV were men (DDI, 2016). Historically, the most common modes of HIV transmission in Portugal have been through heterosexual unprotected sex $(38 \%)$ and the use of contaminated injection equipment for intravenous drug use (44.7\%; Pereira, 2014). Approximately $12.4 \%$ of all infections were transmitted via homosexual and/or bisexual unprotected sex (cumulative percentage of HIV infection transmission from 1983 to 2011; DDI, 2016). It is particularly important to mention that the rate of transmission among men who have sex with men (MSM) in Portugal has doubled since 2001, and that these estimates only included notified cases, and did not consider any unreported cases (Pereira, 2014). Therefore, MSM persist as one of the most at-risk groups for HIV transmission (Lorimer et al., 2013; Pereira, 2014), which has been exacerbated by the fact that there is a higher risk of HIV transmission during unprotected anal sex in comparison to vaginal sex given the same conditions (Hart et al., 2016). Having an HIV diagnosis impacts the emotional and sexual

Henrique Pereira, PhD, is an Assistant Professor, University of Beira Interior, Covilhã, Portugal. (*Correspondence to: hpereira@ubi.pt).Denise Caldeira, MSc, is a Clinical and Health Psychologist, University of Beira Interior, Covilhã, Portugal. Samuel Monteiro, PhD, is an Assistant Professor, University of Beira Interior, Covilhã, Portugal. 
lives of MSM, whether it is via the adoption of periods of sexual abstinence following diagnosis, which many consider to be a period of adaptation to life under these new conditions, or feelings of insecurity, concerns about transmission, or the negotiation of sex and relationships as a person living with HIV (PLWH; Grace et al., 2015; Wei et al., 2014).

After an HIV diagnosis, re-engaging in sexual intercourse usually involves ensuring effective treatment, a decreased viral load, managing dating and relationships, interacting with seroconcordant/serodiscordant people, receiving support from counseling services and friends and family, and satisfying one's partner (Grace et al., 2015). The knowledge of one's viral load becomes relevant because a low viral load has been associated with a decreased risk of HIV transmission, and therefore, has a significant impact on the resumption of sex and relationships (Wu et al., 2015).

Antiretroviral therapy (ART), taken consistently, can limit and control HIV replication while reducing the viral load to undetectable levels (Wu et al., 2015), and the early and successful treatment of PLWH using ART contributes to a significant reduction in the chance of the HIV transmission (Pereira, 2015). Thus, an undetectable viral load has been seen by many MSM as a milestone for re-engaging in sex and relationships, disclosing their HIV diagnosis to sexual partners, increasing sexual freedoms, and lessening concerns about HIV transmission (Grace et al., 2015).

Furthermore, the increased use of ART has been associated with a significant decrease in HIVrelated mortality, despite the fact that transmission still occurs, via undiagnosed individuals or by individuals who were treated without success (Pereira, Monteiro, Esgalhado, \& Afonso, 2015). On the other hand, ART also helped to decrease HIV progression in the Western world (Herrmann et al., 2013), which led to the realization that having an undetectable viral load reduced the risk of HIV transmission (Boom et al., 2013).

More recently, ART prescribed for uninfected individuals (preexposure prophylaxis) has been shown to reduce HIV transmission in vulnerable populations, such as MSM; relevant studies concluded that risk perception played an important role in adherence to this type of treatment (Jayakumaran, Aaron,
Gracely, Schriver, \& Szep, 2016). The use of preexposure prophylaxis prevents new HIV infections while maintaining low or undetectable viral loads (Veloso, Mesquita, \& Grinsztejn, 2015).

Lack of knowledge regarding HIV status still remains an important barrier to HIV treatment. The most common reasons for the lack of HIV testing are (a) stigma (e.g., the fear of bringing shame to one's family); (b) discrimination against MSM and PLWH; (c) the impact of relationships and characteristics of sexual partners in regard to the ease of getting tested for HIV; (d) the presence of a low perceived risk or threat; and (e) concerns related to confidentiality (Wei et al., 2014). Combating stigma and discrimination may appear to be a solitary task for many MSM, and isolation may act as a hindrance in the negotiation of safe sex practices, such as condom use (Hubach et al., 2015). Thus, risky sexual behavior by MSM living with HIV may be viewed as a coping mechanism or as a mediator of psychological stress.

In fact, the most common stigma-associated symptoms among MSM living with HIV include depression (fatigue, desperation, hopelessness, emotional withdrawal); anxiety (catastrophizing, fear of losing control, being easily frightened); interpersonal fears (difficulties seeking stable relationships and intimacy); and the fear of suffering adverse socioprofessional circumstances (anticipating unemployment or poverty; Li, Holroyd, Lau, \& Li, 2015). Drug and alcohol abuse have also been prevalent, and can be seen as a coping strategy after an HIV diagnosis or as facilitators for greater social connection obtained through risky sexual behaviors by MSM (Edelman et al., 2016).

Hence, as Yuh, Ellwanger, Potts, and Ssenyonga (2014) found, HIV-related stigma can result in silence, denial, self-blame, rejection, violence, selfisolation, and serious difficulties revealing HIV status to others, in addition to exclusion and the inability to seek testing and treatment (Cloete, Simbayi, Kalichman, Strebel, \& Henda, 2008). MSM with HIV have often had to deal with several types of stigma. Internalized stigma among MSM living with HIV involves experiences and feelings of shame and fear, driven by the assumption that others will treat them negatively, and the belief that they are to blame for their health condition or for the negative 
way in which others treat them (Jeffries et al., 2015). External stigma involves facing HIV-related prejudice and discrimination in social institutions, leading MSM to less frequently disclose their HIV status or get tested for HIV, poorer treatment adherence (Karamouzian, Akbari, Haghdoost, Setayesh, \& Zolala, 2015), a decline in overall quality of life (Holzemer \& Uys, 2004), and an increase in the number of people who have never been tested for HIV ( $\mathrm{Hu}$ et al., 2014).

MSM who are living with HIV have stated that they are aware of HIV-related stigma, either through subtle attitudes (e.g., body changes that show discomfort) or through more discriminatory behaviors (e.g., the use of phrases such as "contaminated" or "spoiled commodity"; Jeffries et al., 2015), and that being labeled (e.g., "poor things") also serves as a trigger for new forms of discrimination. This may be a more invisible type of discrimination, but, to many, it hurts just as much as any other source of stigma (Gonçalves, Boyce, \& Aggleton, 2016).

MSM living with HIV may suffer from various types of stigma, such as being afraid to be seen in an HIV clinic, in addition to stigma related to their sexual identity (Herrmann et al., 2013), which can act as a barrier to revealing their HIV status, as well as to the avoidance of HIV-related issues (Jeffries et al., 2015). Stigma-related generalizations may involve assumptions such as that MSM are sexual perverts, do not deserve pity, and are sexually immoral (Wu et al., 2015). Another common HIVrelated stigma is that MSM living with HIV do not disclose their HIV status to sexual partners, and that they should only engage in seroconcordant relationships and sexual interactions (Przybyla et al., 2013).

In some cultures, aggressive and hostile attitudes toward same-sex sexual practices are common, often because they are related to the idea that HIV is punishment for individuals who engage in homosexual behavior (Nelson et al., 2015), or that MSM do not behave within the normative parameters of masculinity, or that they do not act in accordance with socially defined gender roles (e.g., a man should not be effeminate). These attitudes cause MSM to experience direct discrimination and stigma, leading to marginalization, which, in turn, contributes to sexual vulnerability (Thomas et al., 2012). Thus, HIV-related stigma is a complex process involving multiple viola- tions of human rights, social oppression, and marginalization (Nelson et al., 2015).

The perpetuation of HIV-related stigma is especially evident among Black MSM living with HIV. Several studies have shown that the Black community continues to stigmatize both homosexual behavior and HIV infection. For this reason, Black MSM suffer a series of stigmatizing behaviors from organizations in the mainstream community as well as from family and friends (Bird \& Voisin, 2013). In many cases, Black MSM living with HIV suffer from triple discrimination because they feel they are a minority within another minority, because they are Black, have sex with men, and have HIV infection (Gonçalves et al., 2016).

Direct experiences and interactions with PLWH have been positively associated with a decrease in the levels of HIV stigma (Prati et al., 2016) and, therefore, a higher probability of seeking HIV testing and obtaining effective social support (Pereira, 2015). Thus, there is a need for effective services and strategies to create the conditions for decreasing HIVrelated stigma, thus promoting greater treatment adherence (Wei et al., 2014). According to Grace and colleagues (2015), HIV prevention can be accompanied by improved skills such as more effective condom use.

It is important to promote psychological wellbeing in MSM living with HIV, while intervening to neutralize the stigmas of HIV and MSM. These strategies could include promoting education about HIV, helping society understand how prejudice may lead to vulnerability, and increasing social support from close friends and health care providers (Jeffries et al., 2015; Sun, Wu, Qu, Lu, \& Wang, 2014). Educating the general population would play a prominent role in this endeavor, as it could contribute to a reduction in HIV infections (Jayakumaran et al., 2016). Additionally, health care providers who work with MSM living with HIV must also be educated, because the lack of knowledge among some professionals still represents a potential barrier to MSM accessing HIV health care services, which, in turn, will contribute to increased spread of the virus (Windsor, Benoit, Ream, \& Forenza, 2013).

Not much information is available on the psychological well-being of PLWH who are exposed to HIV- 
related stigma and who adhere to HIV treatment. In addition, little information is available on how MSM living with HIV perceive HIV-related stigma in the era of undetectable viral loads and how they interact with social conditions and environments under these circumstances. Therefore, the purpose of our study was to explore HIV-related stigma perception in MSM living with HIV, deepening our understanding of how to decrease stigma and, consequently, to lower stigma-related behaviors such as risky sexual behaviors, substance abuse, and the failure to undergo HIV testing.

\section{Methods}

\section{Recruitment and Interview}

We recruited a sample of 37 Portuguese MSM living with HIV infection. Information about the study was disseminated through Portuguese lesbian, gay, and bisexual associations and community centers (e.g., ILGA-Portugal, Opus Gay Association), as well as through mailing lists and social networks (e.g., members of nongovernmental agencies and organizations that worked with lesbian, gay, and bisexual people, Internet forums, Facebook). Participants responded to online outreach through a Website created for this purpose.

The study was approved by the Ethics Committee of the University of Beira Interior (Portugal), and the research data safety benefit from the researchers' university affiliation and its most recent and updated technological mechanisms for protecting data collected in Web data interactions. Participants were asked to read and agree to an informed consent waiver and to acknowledge voluntary participation in the study, as well as to indicate that they were cognizant of confidentiality issues. The online site presented the study's objectives and included all of the principles of traditional research ethics, including confidentiality, anonymity, and informed consent. We complied with all ethical principles established by the Portuguese Board of Psychologists, as well as the guidelines of the American Psychological Association. We anticipated that each participant would take about 15 minutes to respond to the survey and the interview, taking advantage of the online asyn- chronous recruitment process as an enhanced opportunity to respond and discuss more sensitive topics.

Participants were recruited online and invited to fill out a survey and e-mail interview, both of which were conducted between October 2016 and January 2017 (Pereira \& Monteiro, 2016). A total of 500 contacts with MSM were established. Inclusion criteria included the following: being more than 18 years of age, self-identified as MSM, living in Portugal, being a native Portuguese speaker, and being infected with HIV with an undetectable viral load (as confirmed by the participant's last medical examination). All of those who responded were invited to complete a structured inquiry consisting of a short section of sociodemographic questions concerning the participant's age, place of residence, occupation, education, relationship status, date of HIV diagnosis, AIDS diagnosis, selfperception of mental and physical health, and adherence to ART. Subsequently, participants were asked to respond to another section with questions designed to meet the study's main topics and objectives. The authors developed a set of 10 open-ended questions to guide the electronic data collection process (see Table 1). Online interviews, conducted in nonreal time, facilitated via e-mail, are increasingly being used for data collection by social scientists, and are a simple mode of online interaction ( $\mathrm{O}^{\prime}$ Connor \& Madge, 2008). Online interviewing by e-mail contact was considered the best alternative to share about sensitive topics (e.g., HIV infection, intimacy, sexuality) with greater openness and genuineness.

\section{Data Analysis and Tools}

Our data consisted of direct transcriptions imported from written information contained in the electronic questionnaires. We used thematic analysis to search, identify, and analyze repeated patterns of meaning throughout the data. "Thematic analysis ... is not tied to a particular theoretical outlook and so can be applied when using a range of theories and epistemological approaches" (Joffe, 2012, p. 211). Thematic analysis is inductive, as were data obtained from the semantic content and latent constructs inherent in participants' written responses (Braun \& Clarke, 2006). This process consisted of familiarization with the data, followed by generating initial codes, searching for basic themes, reviewing 
Table 1. Questions in the Electronic Interview

1. How do you think the people around you deal with you being HIV-positive?

2. What makes you communicate (or not communicate) to others that you are HIV-positive?

3. How does being HIV-positive interfere with your daily life?

4. How does being HIV-positive interfere with your sexual behavior with other men (when it comes to looking for sex)?

5. How does being HIV-positive interfere with your romantic behavior with other men (when dating or wanting to engage in romance)?

6. How does being HIV-positive interfere with your social, family, or professional behavior?

7. How does being HIV-positive interfere with the quality of your interactions with the health care system (family doctor, health technicians, access to health care, etc.)?

8. How does being HIV-positive interfere with your selfesteem/emotional well-being?

9. How does the experience of being gay or bisexual and HIV-positive differ from the experiences of HIV-positive heterosexual men?

10. In your opinion, how can one fight stigma against HIV/ AIDS, specifically among MSM?

$\mathrm{MSM}=$ men who have sex with men.

the themes, defining and naming the themes, and producing a summary report.

The participants' answers were examined by the authors, allowing for analysis of the main issues through a constant comparison process of recurring themes and of the range of variation and nuances of participant responses (Strauss \& Corbin, 1990). The consistency of coding was assessed by comparing classifications made independently by the authors. In cases where classifications did not match, the coders discussed the differences, working together to reach a consensus solution.

Transcribed texts from all interviews were inserted into a software program for organizing data and conducting text searches (NVivo, version 9; QSR International, Doncaster, Victoria, Australia). Data content analysis was used to identify information and concepts that emerged from the text analysis and were subsequently organized and linked together (Ryan \& Bernard, 2000). All transcripts were independently examined and cross-validated by two readers (Strauss \& Corbin, 1990), thus identifying broader themes that emerged from the interviews. Based on thematic analysis, the broader themes were organized, assessed, and analyzed for the presence of secondary topics. Illustrative quotations were used to support results followed by a fictitious name (assigned by the authors) and their real ages (see below). During data collection, each participant was identified by a randomized code number.

\section{Results}

Of the 500 initial contacts, 37 men fully responded to the two questionnaire sections and, thus, comprise the sample for our analysis. The men were 41.66 years of age on average $(S D=9.62)$, with participant ages ranging from 26 to 67 years. On average, our participants were diagnosed with HIV infection 10.69 years ago $(S D=8.09)$, with diagnosis dates ranging from 1 to 30 years ago. Table 2 shows details of the sociodemographic information of the 37 study participants.

\section{External Perceptions of HIV-Related Stigma}

Most of our participants indicated significant levels of uncertainty when anticipating how other people would react to their HIV status. Opinions ranged from acceptance to discrimination, from disinterest to fear. This motivated many participants to refrain from disclosing their HIV or to be selective in the people with whom they were willing to share this information.

It depends. I anticipate that some people will react very badly, and others without any issues, especially if they are well informed. Nevertheless, in general I don't tell, because I know many people are prejudiced, so it's best that they know nothing about that. Joaquim, 47

Many of my close friends know that I'm HIV positive. At first, their reaction was shock, but with some explanation they became more and more at ease with the situation. This would not be the case if I wanted to be more than just friends with some of them, so this is the borderline of separation between being just friends and being something more. Manuel, 39

Participants also described having to deal with social stigma rooted in negative beliefs and (mis)representations of the disease in combination with homophobia. 
Table 2. Demographic Characteristics $(n=37)$

\begin{tabular}{|c|c|c|c|c|}
\hline & $n$ & $\%$ & $M$ & $S D$ \\
\hline \multicolumn{5}{|l|}{ Age in years } \\
\hline Range $=26-67$ years & & & 41.66 & 9.62 \\
\hline \multicolumn{5}{|l|}{ Date of diagnosis (years ago) } \\
\hline Range $=1-30$ years & & & 10.69 & 8.09 \\
\hline \multicolumn{5}{|l|}{ Education } \\
\hline Up to 12 years of schooling & 11 & $29.7 \%$ & & \\
\hline Some university & 19 & $51.4 \%$ & & \\
\hline University degree & 7 & $18.9 \%$ & & \\
\hline \multicolumn{5}{|l|}{ Marital status } \\
\hline Single & 25 & $67.6 \%$ & & \\
\hline Married to a man & 2 & $5.4 \%$ & & \\
\hline De facto union with a man & 7 & $18.9 \%$ & & \\
\hline Divorced & 3 & $8.1 \%$ & & \\
\hline \multicolumn{5}{|l|}{ Place of residence } \\
\hline Large urban environment & 25 & $67.8 \%$ & & \\
\hline Small urban environment & 9 & $24.3 \%$ & & \\
\hline Large rural environment & 1 & $2.7 \%$ & & \\
\hline Small rural environment & 2 & $5.4 \%$ & & \\
\hline \multicolumn{5}{|l|}{ Ever received an AIDS diagnosis? } \\
\hline Yes & 7 & $18.9 \%$ & & \\
\hline No & 28 & $75.7 \%$ & & \\
\hline Don't know & 2 & $5.4 \%$ & & \\
\hline \multicolumn{5}{|l|}{ Antiretroviral treatment } \\
\hline Yes & 32 & $86.5 \%$ & & \\
\hline No & 5 & $13.5 \%$ & & \\
\hline \multicolumn{5}{|c|}{ Self-assessment of physical health } \\
\hline Excellent & 17 & $45.9 \%$ & & \\
\hline Good & 11 & $29.7 \%$ & & \\
\hline Reasonable & 7 & $18.9 \%$ & & \\
\hline Poor & 2 & $5.4 \%$ & & \\
\hline \multicolumn{5}{|l|}{ Self-assessment of mental health } \\
\hline Excellent & 13 & $35.1 \%$ & & \\
\hline Good & 14 & $37.8 \%$ & & \\
\hline Reasonable & 6 & $16.2 \%$ & & \\
\hline Poor & 4 & $10.8 \%$ & & \\
\hline
\end{tabular}

Society is discriminatory, that's for sure, and I feel discrimination because I'm gay, and because I'm HIV positive. People still think that HIV-positive people are doomed to die tragically. Unfortunately, people still see us as promiscuous, sick, and intolerable. I still feel stigma, as if I was doomed or cursed for being gay, and as if being HIV positive were a punishment for being gay. Luís, 42

Something funny happened to me. My mother was less alarmed when I told her that I was HIV-positive than when I told her that I was gay. It was like in her mind it made sense that a gay man would be HIV positive anyway, and that gave her some sense of congruence. $\mathrm{Ri}$ cardo, 51

In addition, some men indicated the importance of having an undetectable viral load as a mediator of the negative impact of stigma and discrimination. One participant specifically said:

People around me see me as a healthy man, going to the gym and being active, so they don't associate their image of the disease with the way I look. Having an undetectable viral load allows me to feel healthy, and people simply don't imagine that I'm HIV positive, and I also don't give them that information. I prefer to keep things as they are. Paulo, 27

\section{HIV Status Disclosure}

The majority of our participants chose not to disclose their HIV status to other people mainly because of the fear of losing family member and friend support, and/or because of the anticipation of facing discrimination, a lack of trust, and fear of rejection.

I don't talk about my problem, generally, and the reason is because I know that I will be discriminated against. It's a serious matter, and I only share it with people whom I absolutely trust, that I know for sure that won't marginalize me. Gonçalo, 48

I usually say that I'm HIV positive when I want to have sex. This way I get to meet other HIVpositive men and things are easier this way. Sometimes I talk to HIV-negative men for sexual purposes, and I also tell them that I am HIV-positive, and even if I have to deal with their rejection, I think it's my obligation to inform them of that, and then they decide whether they want to have sex with me or not. It's important for me to do this, because I like bareback sex, and being undetectable gives me this sense of freedom. João, 38

Other men described the fear of feeling or inflicting sorrow as the motivation for not disclosing their 
HIV status in close relationships, indicating a form of internalized stigma.

I only told some friends because there was another case in our circle of friends, so I knew that they would be accepting of me. Yet, I never told my family because I don't want to cause them such anguish, as this would be unnecessary, so I decided to spare them. André, 33

On the other hand, several participants talked about the need to disclose their HIV status as an effective way to seek support and engage in sex or significant relationships. As some of our participants said: "I specifically state in my Manhunt profile that I am HIV positive, and that I am only there for sex. Therefore, those who hit me up already know that information, and don't make me waste my time" (Hugo, 30). Bruno (55) said, "I don't want to bear this burden alone. It's hard to deal with this without sharing my anxieties and insecurities with anyone. So, I shared it with my siblings and close friends, who I know can somehow be supportive." And Francisco (46) said,

I only tell other gay men that I'm HIV positive after dating for a while, and when I anticipate that we can become more than just friends. Of course, this makes it even harder, but it's the only circumstance when I find it reasonable to tell others. Investing in a relationship is very meaningful to me, so I have to be honest, even if it implies a lot of risk. I've had men turn their backs on me at a restaurant after dating for a month or 2, just after communicating that I am HIV positive. Before, it used to break my heart; now I am more resigned.

Some participants also questioned the idea of having to disclose their HIV status as an imposition that should be challenged. This questioning had to do with the fact that they were healthy, and found no specific reason to disclose, whatsoever. For example,

I don't feel the need to communicate this information to anyone. When it comes down to it, what is important is to assess the relevance of HIV in my everyday life, taking my medications, going to my medical appointments, etc. It doesn't affect my coworkers, my relatives, strangers, or my friends. So, who cares? It's my business. Nuno, 40

\section{Impact on General Everyday Life}

Ninety percent of our participants stated that having HIV infection with an undetectable viral load did not interfere with their general everyday lives. The remaining said that relevant obstacles had to do with taking antiretroviral medication (accessing medication and dealing with its side effects), and having to take special precautions to prevent risk exposure. Fernando (58) said, "I usually lead a very normal life, but having to conciliate work schedule with my medication schedule can be troublesome to me. I do not always remember to take my medication, and this bothers me a lot." And Marcos (44) said, "For me, the main obstacles are dealing with some of the side effects of the antiretroviral medication, especially insomnia, vomiting, and diarrhea."

Two participants expressed a negative impact on their self-esteem and mood, emphasizing social exclusion and the inability to socialize with others.

I used to be a very handsome, successful, and interesting man, but after becoming HIV positive, everything changed. It affected my selfesteem, I feel excluded and isolated, and it's very hard to meet other men. I feel very depressed and excluded. Carlos, 26

The awareness of the disease is very uncomfortable. In my everyday life I don't usually remember, but when I do, I feel a resurgence of consciousness of my status, along with panic and fear. This restricts my ability to express myself and to meet people. It limits me. Gonçalo, 48

\section{Impact on Sex Life}

The impact of having HIV and an undetectable viral load on the participants' sex lives ranged from taking safer sex precautions to abstaining from sex, depending on whether they had a partner or not. For some, it made them become more sexually active, while for others, it made them become more selective.

Despite the fact that I am undetectable, I always play safe. I am more responsible and careful, and I always use protection. I let my partners know that I am HIV positive, and this affects my own awareness regarding the specific sexual activity. For example, I always use a condom for 
oral sex and for anal sex to avoid reinfection. While I am having sex, all this information is on my mind, I become very attentive to all the details, and sometimes it makes me feel less focused and less excited during sex. Sérgio, 35

I always prefer to have sex with other HIVpositive men who also have an undetectable viral load. I have no patience or emotional availability to deal with the stress that derives from having sex with HIV-negative men, because they are so afraid of infection, that they would simply discard you like garbage if they knew. I prefer to let things happen naturally, while playing safe, so I only want to have sex with other HIV-positive men to avoid any hassle. Tiago, 46

For some men, having HIV with an undetectable viral load caused them to have more sex, to be more committed to engaging in casual sex, and to decreased concerns about HIV transmission.

I became more promiscuous. Maybe the fact that being undetectable reassures me that I won't infect anyone makes me want to have anonymous sex, as often as I can. I don't really tell or ask about HIV, and I always focus on sex. I've had men wanting to keep in touch with me, but I have always refused, not because of any possible HIV transmission, but because having a social relationship with them would eventually lead to the disclosure of my HIV status, and I don't want that. Also, I enjoy sex a lot more, I'm always willing to try new things and explore my sexual limits. I know it would be different if my viral load was not undetectable, so I have a lot of fun. Rui, 34

I got HIV from my partner, so it really affected my relationship, and we are not together anymore. Being alone and surviving this trauma has had a huge impact on my sex life. I don't feel any interest in casual sex, so I just masturbate. Carlos, 26

\section{Impact on Social, Family, and Professional Life}

Again, most men report no impact on their social, family, or professional life, but this was mainly due to a lack of disclosure. Keeping their HIV status secret allowed certain levels of emotional safety.
In a sense, being HIV positive has allowed me to think deeply about my life, and the quality of my important relationships, and this has made me grow as person. In turn, I see myself as a man who has healthier personal and professional relationships. It makes me value what I have more, my family, my friends, and my job. It's not all bad. Daniel, 48

Up until now, it hasn't interfered in my life because I haven't told anyone, and I am currently unemployed. Maybe if I had to do a medical examination for a future job this would become a problem, but, up until now, I haven't really had any problems. André, 33

It only interferes because, sometimes, I have to hide from my coworkers so I can go to the washroom to take my medication. Being HIV positive also affected me professionally when I was fired from my old job for being HIV positive. I know it was illegal, but I didn't do anything because I didn't want to deal with the exposure that would come from that. The insurance company forced HIV tests, and my employer decided that he didn't want an HIVpositive employee. Roberto, 60

\section{Impact on Emotional Well Being}

Only a few men stated that they were not affected by emotional factors. In fact, most said that they had trouble coping with emotional challenges, such as emotional instability, anxiety, depression, suicidal thoughts, feelings of abandonment, disappointment, and low self-esteem. Despite this, it became clear that the main source of emotional obstacles was the lack of social and/or family support that could work as a mediator of the negative impact of HIV-related social stigma.

Sometimes I feel lonely and abandoned, but then I realize that feeling this way only worsens my emotional state, so I hold my head up high and move on. There was a time when I considered suicide, because everything seemed so 
tough, especially when confronting my fears or trying to have relationships. José, 67

I remember being psychologically unstable prior to becoming HIV positive, so when I found out about my status over 10 years ago, I almost destroyed myself. Times were different back then, and fortunately I was able to digest things and cope with the consequences of my condition. But the main adversity I face is having to deal with the anticipation of rejection, and not the physical aspects of the disease. Alberto, 53

I am constantly looking for ways to increase my self-esteem, and it's not always easy. This is directly connected to the anticipation of rejection by someone I like. When I generate expectations toward someone nice, and want to make things more intimate, the results are usually catastrophic and they usually turn their back on me after finding out that I am HIV positive. The repetition of this cycle is exhausting and can make me not want to get out of bed in the morning. Maybe I still haven't fully accepted my condition, I don't know, but it really makes me sad. Vítor, 36

Some men also spoke about how the need to constantly be cautious in order to avoid discrimination (and not the fact that they were infected with HIV in and of itself) entailed dealing with significant amounts of stress and anxiety because of the need to hide their HIV status.

I think that it affects my attitude. I become less positive and less confident, because I deal with the constant need to hide my HIV status. Living in constant stress and fear affects my performance at work. I cannot disclose my status because I know that there is a lot of misinformation and discrimination, and I am certain that I would be fired. Sometimes I feel depressed and exhausted, and people notice it, but I just tell them that I am tired from work. Nevertheless, they don't have a clue about my condition. António, 42

\section{Double Discrimination}

Some men talked about their beliefs regarding gay and bisexual men being more sexually active than straight men, and how this led to greater exposure to HIV infection and risky sexual behavior. On the other hand, some men also described the double discrimination derived from having HIV and belonging to a sexual minority, thus becoming more susceptible to the negative effects of prejudice and discrimination when compared to straight men.

I think that gay men have more sexual partners than straight men, and this forces them to be more careful to avoid reinfection and infecting others. But having safe sex is different from having to deal with the fact that a straight HIVpositive man doesn't have to deal with homophobia. It's easier for them, I guess. Fábio, 63

\section{Impact on the Interaction with the Health Care System and/or Access to Health Care}

Almost all of our participants were being treated with ART. In Portugal, HIV treatment is universal and free of charge, and includes regular health care, as long as the patient adheres to the prescribed treatment. All of the men mentioned that they were satisfied with the health care system and that they had had no major obstacles when accessing health care. The only exceptions were when their routines changed, for example, when going on vacation or when moving to a different address, and some men experienced obstacles informing and adapting to the health care system's approach to these changes. Overall, all of the men said that their health care professionals were well informed and that they had no reason to complain and, thus, were satisfied with the quality of their health care interactions.

Some men, however, described how they could see themselves as obstacles to their own adherence to treatment and to undergoing medical examinations. In many cases, the anticipation of shame or rejection delayed participants from seeking HIV testing or spurred their resistance to ART, due to the negative beliefs they associated with HIV.

Now it's very easy for me to go the doctor, because she is very professional and doesn't judge me at all. But this was not the case before, when I used to feel ashamed and fearful. It took me a lot of courage and time to get an HIV test 
and I remember thinking, "What if someone sees me at the hospital? What if they judge me for being gay or for having unprotected sex?" Finally, I was able to trust the health care system and "normalize" the situation, viewing HIV testing and treatment as I would view any other medical procedure. Bernardo, 32

\section{Impact on Romantic Behavior}

Most men said that the anticipation of rejection by uninfected men led them to dismiss any romantic expectations or confine them strictly to other men living with HIV. This was the case for the $75 \%$ of our participants who were single. As those who were already in a relationship were all seroconcordant, their relationships served as the main source of social and emotional support. However, their relationships also were the principal reason for eventual challenges regarding relationship behavior, such as communication, expressing intimacy, and deciding to have an open relationship and to allow sexual activity with others. Still, when seeking romance, most men had to deal with the anxiety of disclosing their HIV status, and most excluded disclosure from their lives.

I know that it's very hard for an HIV-negative gay man to be with an HIV-positive gay man. I never know what to expect. Besides rejection, they may also share this information, exposing me to other people, and this would be chaotic. So, I stick to the possibility of finding a boyfriend who is also an HIV-positive man, but I know that this condition is not sufficient to like the person. So, I guess it's more likely that I will end up alone, and I will have to deal with it. Pedro, 33

This has been my foremost concern for the past decade. All attempts at finding someone to share my life with failed, and this huge fear of rejection has built up, leading me to a very isolated place. So, I simply avoid it, but I feel very needy, and sometimes I use sex to feel a bit more acceptance, even if it's just for a few minutes. Jaime, 42

I don't want any romance in my life. I didn't think it was necessary before I got HIV, and I definitely don't think it is now. Maybe this is a defense, but all my HIV-positive friends who have romantic expectations are constantly dealing with rejection, and I don't want to go through that. I've also had my share of disappointment. Gustavo, 38

Some men mentioned that having HIV didn't interfere with the possibility of interacting with other men for romantic purposes. In fact, several mentioned the strategy of preferring other HIV-positive men to engage in romantic relationships, while others mentioned that they felt the need to be honest with potential partners and disclose their HIV status at the beginning of their interactions.

It's not easy to disclose my HIV status to a man when there is a great probability of being rejected by him, but I have to be at peace with my conscience, and I still believe that there is someone out there who will love me for who I am, and not for my HIV status. Having a relationship is hard for all people, for gay people, and for HIV-positive gay people, so I know what my chances are, I just accept it. Rodrigo, 32

\section{General Perceptions of HIV-Related Stigma}

Most men still perceived the lack of information and HIV prevention campaigns as the main source of HIV-related stigma, because they thought greater availability of information would lead to a better general understanding of HIV, a shift in mentalities, and more openness regarding broader issues, such as information concerning sexual minorities.

I think stigma exists because of a lack of visibility. How many HIV-positive public figures do you know? It's understandable that people need to protect themselves from discrimination, but, at the same time, this perpetuates ignorance and prejudice. What we need to do is to "normalize" HIV through accepting it and making it just as "normal" as any other disease. If we can do this, HIV will be just like diabetes, or any other disease, and people don't deserve to be judged because of that. Júlio, 49

Stigma affects everyone, whether gay, bi, or straight. Ending it can only be done through educating everybody, not only those infected 
with HIV but also those affected by HIV, family, friends, so that everybody learns and adapts to living together with the virus. Testing, medication, nutrition, social life, treatment progress, and fighting stigma all involve the complexities of understanding the disease with no room for prejudice. Tiago, 46

With the right amount of education campaigns, we could discard all the old information that is very stigmatizing and replace it with current, updated, and accurate information that conveys the reality of HIV today. It's unfair that HIV-positive people have to deal with discrimination and prejudice in the $21^{\text {st }}$ century. We can live healthy, long lives because of our undetectable viral loads and healthy choices, and we deserve to be as happy as any other human being. Miguel, 40

\section{Discussion}

Having an undetectable viral load is important because it allows the immune system to recover and become stronger, thus lowering the risk of becoming ill due to HIV, reducing the risk of developing other serious illnesses, decreasing the risk of HIV becoming resistant to antiretroviral medication, and, finally, minimizing the risk of HIV transmission to someone else. Therefore, the reality of having HIV with an undetectable viral load creates new circumstances for social interactions and new forms of HIV-related stigma that are still unclear. The main purpose of our research was to explore the specificity of HIV-related stigma in MSM living with HIV and an undetectable viral load.

One of the main findings from our study was that HIV was still regarded as a socially disabling disease with a great degree of stigma in Portugal, with MSM referring to stigmatizing and discriminatory behaviors and practices at the psychosocial and inter-relational levels, but not when accessing and receiving health care, which was consistent with the results of other studies (Cloete et al., 2008; Grace et al., 2015; Hubach et al., 2015; Jeffries et al., 2015). Our participants argued for the normalization of HIV, and pointed out that the social invisibility of HIV interfered with fighting stigma in different ways. This may be a reason why most men in our study chose not to disclose their HIV status to others, while feeling marginalized and disempowered at the same time (Hosek, Harper, Lemos, \& Martinez, 2008) because of a fear of rejection.

Living with an undetectable viral load impacts sexual opportunities and experiences in complex, evolving ways. The analysis of participant responses concerning being sexually active after a recent HIV diagnosis revealed interrelated social, psychosocial, and biomedical issues that were differentially negotiated, ranging from withdrawing from sex to becoming more sexually active. This highlighted the importance of improving personal sexual health literacy and understanding the efficacy of HIV treatments, as participant accounts also illustrated risk comfort levels, while underscoring that sexual health education must not simply disseminate the biomedical facts of HIV transmission, but also meaningfully account for the reality that different people have varying levels of risk tolerance.

Furthermore, participant narratives illustrated that an HIV diagnosis was much more than a biological disruption that might be restored through the use of medication, as many men reported a significant biographical disruption (Bury, 1982) of both an acute and chronic nature related to their social and sexual lives. We argue that our participants' narratives helped conceptualize the emergence of undetectability as an autonomous identity regarding social and interpersonal interactions. However, the men's accounts of their sex lives after diagnosis revealed some of the ways in which the discourse of undetectability was actively co-constituted and reproduced, as it played out in everyday sexual and social lives. This discourse often concerned the anticipation of discrimination and rejection, low expectations about forming significant relationships, the lack of HIV status disclosure, enabling and/or rejecting certain sexual possibilities, the rationale for continuing treatment, the sources of emotional support and personal growth, and, for some, the sources of discomfort, instability, or confusion.

Participant self-descriptions revealed a number of tensions linked to living with HIV in Portugal. On one hand, the men in our study sought a level of social recognition that included the awareness of their 
needs and a degree of visibility. On the other hand, practices such as not telling others about having HIV were also observed. This contradiction pointed to parts of the unwritten story of the epidemic to date, namely, the tension between the external and internal dimensions of HIV-related stigma and discrimination in a context where ART is readily available, a scenario that warrants further investigation. Similarly, stigma reduction interventions could help to manage these issues, strengthen the focus on the experiences of PLWH, and improve their psychosocial well-being. Our study also contributed to a deeper insight into the complexities of structural factors associated with experiences of living with HIV, which may resemble the experiences of those living in similar settings. As a result, not only did we provide an opportunity for men to discuss issues that were often forgotten, it also highlighted the need for stigma-reduction strategies that acknowledge the intricacies of living with HIV in developed countries.

The results of other studies with Portuguese MSM (e.g., Gonçalves, et al., 2016; Pereira, 2014; Pereira \& Monteiro, 2016) have indicated that cultural variables may also be important in understanding MSM responses to HIV-related stigma and its influence on their attributions of importance to personal quality of life and well-being, as cultures transmit values and expectations that impact the social and sexual behaviors of their members. It is critical that we understand cultural influences and behaviors relevant to HIV risk taking in order to reduce the further spread of HIV (Pereira, 2014).

The double exposure of participants to levels of stigma associated with being gay and having HIV was also an important finding. Portuguese culture still restricts the identity development of MSM through negative societal attitudes, generally resulting in the internalization of stigma associated with sexual and/or gender identity (Costa, Pereira, \& Leal, 2013) and HIV status.

Our findings, as also shown by Carmel, Lohan, Alderdice, and Spence (2011), demonstrated how personal priorities, values, and meanings were central to the negotiation of stigma among MSM living with HIV and an undetectable viral load, in which (bio)medical understandings of risk, especially those based on the biological markers of viral load detection, were balanced against a broader set of social expectations, desires, and sensation seeking (Kelly, Lohan, Alderdice, \& Spence, 2011). In this setting, the erotic culture of Portuguese MSM, the presence of stigma or discrimination, the pressure to reveal their status, in conjunction with the added security of having an undetectable viral load could all lead to the rationalization of how risk is perceived (Pereira, 2014), and this was an important implication of our study, related to multilevel risk perceptions (of the self, the other, and the community) and the psychosocial complexity and challenges of HIV infection. Furthermore, as mentioned by Pereira (2014), this confluence of factors explain why Portuguese MSM may be likely to defend unprotected sex, not only being more pleasurable, but also as signifying a return to a sense of normality in intimate relationships that were affected and weakened by HIV (Dowsett, 2003), by public health messages, and by communication strategies that viewed sexual risk solely through a biomedical lens while denying the psychosocial significance and meaning given to sex and condoms, love, pleasure, and intimacy within a relationship.

\section{Limitations}

Our study was not without limitations. Online contact with participants did not allow for biochemical validation of self-reported HIV status, viral load, or confirmation of medical examination results. There was also potential for selection bias, because the study was disseminated specifically in gay and bisexual-orientated social-networking venues. The sample did not include men who did not frequent these online platforms. Further research, with other sampling strategies, exploring the perceptions of hidden groups of MSM living with HIV and an undetectable viral load would be useful. Second, most participants were well educated, receiving HIV health care, and from urban areas. Future research should include men from more heterogeneous socioeconomic groups and education levels. However, the intention of our qualitative research was not to generalize the findings to all MSM living with HIV and an undetectable viral load, but to provide a space for the voices of this group, so that their perceptions of stigma could be heard. In spite of these limitations, our findings underscore several implications related to the need to identify and combat HIV-related stigma. Several participants emphasized the need 
for public education and an ongoing dialogue to promote more positive perceptions about HIV and MSM and to increase access to treatment for MSM living with HIV. Finally, our study was conducted in Portugal and experiences may be different in other countries.

\section{Conclusion}

Our study illuminated ways in which stigma can adversely affect the well-being of MSM; most participants in our study described how HIV-related stigma led to a reticence to disclose their HIV status, which could result in uninfected men not inquiring about a partner's HIV status before having sex. Other studies similarly described relationships between HIVrelated stigma and these phenomena (O'Leary, 2005; Rao, Kekwaletswe, Hosek, Martinez, \& Rodriguez, 2007). Because stigma could result in MSM being socially ostracized, it may also prevent them from seeking the social support that would be conducive to their overall psychological well-being.

\section{Key Considerations}

- Undetectability as an identity category has important connections to social and interpersonal interactions.

- In Portugal, HIV is still a socially disabling disease.

- There is an urgent need for public education and an ongoing dialogue to promote more positive perceptions about HIV and men who have sex with men (MSM) and to increase access to treatment for MSM living with HIV.

\section{Disclosures}

The authors report no real or perceived vested interests that relate to this article that could be construed as a conflict of interest.

\section{Acknowledgments}

We wish to thank all participants in the study.

\section{References}

Bird J. D., Voisin D. R. (2013). "You're an open target to be abused": A qualitative study of stigma and HIV selfdisclosure among Black men who have sex with men. American Journal of Public Health, 103(12), 2193-2199. http://dx. doi.org/10.2105/AJPH.2013.301437

Boom W., Stolte I. G., Witlox R., Sandfort T., Prins M., Davidovich U. (2013). Undetectable viral load and the decision to engage in unprotected anal intercourse among HIVpositive MSM. AIDS and Behavior, 17(6), 2136-2142. http://dx.doi.org/10.1007/s10461-013-0453-9

Braun V., Clarke V. (2006). Using thematic analysis in psychology. Qualitative Research in Psychology, 3(2), 77-101. http:// dx.doi.org/10.1191/1478088706qp063oa

Bury M. (1982). Chronic illness as biographical disruption. Sociology of Health and Illness, 4, 167-182. http://dx.doi.org/ 10.1111/1467-9566.ep11339939

Carmel K., Lohan M., Alderdice F., Spence D. (2011). Negotiation of risk in sexual relationships and reproductive decisionmaking amongst HIV sero-different couples. Culture, Health \& Sexuality, 13(7), 815-827. http://dx.doi.org/10.1080/ 13691058.2011.563865

Cloete A., Simbayi L. C., Kalichman S. C., Strebel A., Henda N. (2008). Stigma and discrimination experiences of HIVpositive men who have sex with men in Cape Town, South Africa. AIDS Care, 20(9), 1105-1110. http://dx.doi.org/10. 1080/09540120701842720

Costa P. A., Pereira H., Leal I. (2013). Internalized homonegativity, disclosure, and acceptance of sexual orientation in a sample of Portuguese gay and bisexual men, and lesbian and bisexual women. Journal of Bisexuality, 13, 229-244. http:// dx.doi.org/10.1080/15299716.2013.782481

Departamento de Doencas Infecciosas. (2016). Infecão VIH/ SIDA: A situacão em Portugal a 31 de Dezembro de 2015. [[HIV/AIDS: The situation in Portugal on December 31, 2015]]. Lisboa, Portugal: INSA.

Dowsett G. (2003). Some considerations on sexuality and gender in the context of AIDS. Reproductive Health Matters, 11(22), 21-29. http://dx.doi.org/10.1016/S0968-8080(03)02290-0

Edelman E. J., Cole C. A., Richardson W., Boshnack N., Jenkins H., Rosenthal M. S. (2016). Stigma, substance use and sexual risk behaviors among HIV-infected men who have sex with men: A qualitative study. Preventive Medicine Reports, 3, 296-302. http://dx.doi.org/10.1016/j.pmedr.2016. 03.012

Gonçalves R. B., Boyce P., Aggleton P. (2016). Uma nova côr [a new colour]: men's accounts of HIV-related stigma and discrimination in Portugal. HIV \& AIDS Review, 15(3), 106-110. http://dx.doi.org/10.1016/j.hivar.2016.07.001 
Grace D., Chown S. A., Kwag M., Steinberg M., Lim E., Gilbert M. (2015). Becoming "undetectable": longitudinal narratives of gay men's sex lives after a recent HIV Diagnosis. AIDS Education and Prevention, 27(4), 333-349. http://dx.doi.org/10.1521/aeap.2015.27. 4.333

Hart T. A., Willis A. C., Simpson S. H., Julien R. E., Hoe D., Leahy B., Adam B. D. (2016). Gay poz sex: a sexual health promotion intervention for HIV-positive gay and bisexual men. Cognitive and Behavioral Practice, 23(4), 517-529. http://dx.doi.org/10.1016/j.cbpra.2015.11.002

Herrmann S., McKinnon E., Hyland N. B., Lalanne C., Mallal S., Nolan D., Duracinsky M. (2013). HIV-related stigma and physical symptoms have a persistent influence on health-related quality of life in Australians with HIV infection. Health and Quality of Life Outcomes, 11(1), 113. http://dx.doi.org/10.1186/1477-7525-11-56

Holzemer W. L., Uys L. R. (2004). Managing AIDS stigma. SAHARA, 1(3), 165-174.

Hosek S., Harper G., Lemos D., Martinez J. (2008). An ecological model of stressors experienced by youth newly diagnosed with HIV. J HIV AIDS Prev Child Youth, 9(2), 192218. http://dx.doi.org/10.1080/15538340902824118

Hu Y., Lu H., Raymond H. F., Sun Y., Sun J., Jia Y., Ruan Y. (2014). Measures of condom and safer sex social norms and stigma towards HIV/AIDS among Beijing MSM. AIDS and Behavior, 18(6), 1068-1074. http://dx.doi.org/10.1007/ s10461-013-0609-7

Hubach R. D., Dodge B., Li M. J., Schick V., Herbenick D., Ramos W. D., Reece M. (2015). Loneliness, HIV-related stigma, and condom use among a predominantly rural sample of HIV-positive men who have sex with men (MSM). AIDS Education and Prevention, 27(1), 72-83. http://dx.doi.org/ 10.1521/aeap.2015.27.1.72

Jayakumaran J. S., Aaron E., Gracely E. J., Schriver E., Szep Z. (2016). Knowledge, attitudes and acceptability of preexposure prophylaxis among individuals living with HIV in an urban HIV clinic. PLoS One, 11(2), e0145670. http://dx. doi.org/10.1371/journal.pone.0145670

Jeffries W. L. IV, Townsend E. S., Gelaude D. J., Torrone E. A., Gasiorowicz M., Bertolli J. (2015). HIV stigma experienced by young men who have sex with men (MSM) living with HIV infection. AIDS Education and Prevention, 27(1), 5871. http://dx.doi.org/10.1521/aeap.2015.27.1.58

Joffe H. (2012). Thematic analysis. In D. Harper, \& A. R. Thompson (Eds.), Qualitative methods in mental health and psychotherapy: A guide for students and practitioners (pp. 209-223). Chichester, UK: Wiley.

Joint United Nations Programme on HIV/AIDS. (2013). UNAIDS Report on the global AIDS epidemic. WHO Library Cataloguing in Publication Data.

Karamouzian M., Akbari M., Haghdoost A. A., Setayesh H., Zolala F. (2015). "I am dead to them": HIV-related stigma experienced by people living with HIV in Kerman, Iran. Journal of The Association of Nurses in AIDS Care, 26(1), 46-56. http://dx.doi.org/10.1016/j.jana.2014.04.005
Kelly C., Lohan M., Alderdice F., Spence D. (2011). Negotiation of risk in sexual relationships and reproductive decisionmaking amongst HIV sero-different couples. Culture Health and Sexuality, 13, 815-827. http://dx.doi.org/10.1080/ 13691058.2011.563865

Li H. H., Holroyd E., Lau J., Li X. (2015). Stigma, subsistence, intimacy, face, filial piety, and mental health problems among newly HIV-diagnosed men who have sex with men in China. Journal of The Association of Nurses in AIDS Care, 26(4), 454-463. http://dx.doi.org/10.1016/j.jana.2015.02.004

Lorimer K., Kidd L., Lawrence M., McPherson K., Cayless S., Cornish F. (2013). Systematic review of reviews of behavioural HIV prevention interventions among men who have sex with men. AIDS Care, 25, 133-150. http://dx.doi.org/10. 1080/09540121.2012.699672

Nelson L. E., Wilton L., Agyarko-Poku T., Zhang N., Aluoch M., Thach C. T., Adu-Sarkodie Y. (2015). The association of HIV stigma and HIV/STD knowledge with sexual risk behaviors among adolescent and adult men who have sex with men in Ghana, West Africa. Research in Nursing \& Health, 38(3), 194-206. http://dx.doi.org/10.1002/nur.21650

O'Connor H., Madge C. (2008). Internet-based interviewing. In N. Fielding, R. Lee, \& G. Blank (Eds.), The Sage Handbook of Online Research Methods (pp. 271-289). Thousand Oaks, CA: Sage.

O'Leary A. (2005). Guessing games: Sex partner serostatus assumptions among HIV-positive gay and bisexual men. In P. Halkitis, C. Gomez, \& R. J. Wolitski (Eds.), HIV+ sex: The psychological and interpersonal dynamics of HIVseropositive gay and bisexual men's relationships (pp. 121132). Washington, DC: American Psychological Association.

Pereira H. (2014). Condom use and HIV-related behaviors in Portuguese men who have sex with men: A study of sexual behavior and sexual pleasure. AIDS \& Clinical Research, 5(4), 1-5. http://dx.doi.org/10.4172/2155-6113.1000294

Pereira H. (2015). Sexual behavior and HIV testing practices among men who have sex with men in Portugal. Journal of AIDS \& Clinical Research, 6(11), 1-5. http://dx.doi.org/10. 4172/2155-6113.1000524

Pereira H., Monteiro S. (2016). The role of political and legislative changes in the everyday lives of LGB individuals: The case of Portugal. Sexuality Research and Social Policy, 14(3), 300-309. http://dx.doi.org/10.1007/s13178-016-0261$\mathrm{x}$

Pereira H., Monteiro S., Esgalhado G., Afonso R. M. (2015). HIV prevalence and HIV-related sexual practices among men who have sex with men in Portuguese bathhouses. Journal of AIDS \& Clinical Research, 6(1), 1-4. http://dx.doi.org/ 10.4172/2155-6113.1000415

Prati G., Zani B., Pietrantoni L., Scudiero D., Perone P., Cosmaro L., Oldrini M. (2016). The role of knowing someone living with HIV/AIDS and HIV disclosure in the HIV stigma framework: A Bayesian mediation analysis. Quality \& Quantity, 50(2), 637-651.

Przybyla S. M., Golin C. E., Widman L., Grodensky C. A., Earp J. A., Suchindran C. (2013). Serostatus disclosure to 
sexual partners among people living with HIV: examining the roles of partner characteristics and stigma. AIDS Care, 25(5), 566-572. http://dx.doi.org/10.1080/09540121.2012.722601

Rao D., Kekwaletswe T. C., Hosek S., Martinez J., Rodriguez F. (2007). Stigma and social barriers to medication adherence with urban youth living with HIV. AIDS Care, 19, 28-33. http://dx.doi.org/10.1080/09540120600652303

Ryan G. W., Bernard R. (2000). Data management and analysis methods. In N. K. Denzin, \& Y. S. Lincoln (Eds.), Handbook of qualitative research (pp. 769-802). Thousand Oaks, CA: Sage.

Strauss A., Corbin J. (1990). Basic of qualitative research: Grounded theory procedures and techniques. Thousand Oaks, CA: Sage.

Sun W., Wu M., Qu P., Lu C., Wang L. (2014). Psychological well-being of people living with HIV/AIDS under the new epidemic characteristics in China and the risk factors: A population-based study. International Journal of Infectious Diseases, 28, 147-152. http://dx.doi.org/10.1016/j.ijid.2014. 07.010

Thomas B., Mimiaga M. J., Mayer K. H., Perry N. S., Swaminathan S., Safren S. A. (2012). The influence of stigma on HIV risk behavior among men who have sex with men in Chennai, India. AIDS Care, 24(11), 1401-1406. http://dx.doi. org/10.1080/09540121.2012.672717

Veloso V. G., Mesquita F., Grinsztejn B. (2015). Pre-exposure prophylaxis for men and transgender women who have sex with men in Brazil: Opportunities and challenges. Journal of The International AIDS Society, 18(3), 1-6. http://dx.doi. org/10.7448/IAS.18.4.20010

Wei C., Yan H., Yang C., Raymond H. F., Li J., Yang H., Stall R. (2014). Accessing HIV testing and treatment among men who have sex with men in China: A qualitative study. AIDS Care, 26(3), 372-378. http://dx.doi.org/10.1080/ 09540121.2013.824538

Windsor L. C., Benoit E., Ream G. L., Forenza B. (2013). The provider perception inventory: psychometrics of a scale designed to measure provider stigma about HIV, substance abuse, and MSM behavior. AIDS Care, 25(5), 586-591. http://dx.doi.org/10.1080/09540121.2012.726338

Wu X., Chen J., Huang H., Liu Z., Li X., Wang H. (2015). Perceived stigma, medical social support and quality of life among people living with HIV/AIDS in Hunan, China. Applied Nursing Research, 28(2), 169-174. http://dx.doi. org/10.1016/j.apnr.2014.09.011

Yuh J. N., Ellwanger K., Potts L., Ssenyonga J. (2014). Stigma among HIV/AIDS patients in Africa: A critical review. Procedia-Social and Behavioral Sciences, 140, 581-585. http:// dx.doi.org/10.1016/j.sbspro.2014.04.474 